\title{
Examining How Teachers Use Graphs to Teach Mathematics during a Professional Development Program
}

\author{
Alfredo Bautista ${ }^{1,3}$, María C. Cañadas ${ }^{2}$, Bárbara M. Brizuela ${ }^{3}$, Analúcia D. Schliemann ${ }^{3}$ \\ ${ }^{1}$ National Institute of Education, Nanyang Technological University, Singapore \\ ${ }^{2}$ Departamento de Didáctica de la Matemática, Universidad de Granada, Spain \\ ${ }^{3}$ Department of Education, Tufts University, USA \\ Correspondence: Alfredo Bautista, Research Scientist \& Lecturer. Education \& Cognitive Development Lab (ECDL), \\ NIE / Nanyang Technological University. 1 Nanyang Walk. NIE5-B3-16, Singapore
}

Received: January 19, 2015 Accepted: February 3, 2015 Online Published: February 12, 2015

doi: 10.11114/jets.v3i2.676 URL: http://dx.doi.org/10.11114/jets.v3i2.676

\begin{abstract}
There are urgent calls for more studies examining the impact of Professional Development (PD) programs on teachers' instructional practices. In this study, we analyzed how grades 5-9 mathematics teachers used graphs to teach mathematics at the start and end of a PD program. This topic is relevant because while many studies have investigated students' difficulties with graphs, there is limited research on how teachers use graphs in their classrooms and no research on how PD impacts the way teachers use graphs in class to teach mathematics. Participant teachers took three graduate level semester-long courses focused on mathematics and student mathematical thinking. The program provided teachers with multiple opportunities for exploration and discussion, systematic feedback, contexts for collaboration and collegial sharing, and extended follow-up support. We analyzed all lessons where teachers used graphs in class at the start and end of the program, finding that teachers' use of graphs was qualitatively more sophisticated in the end lessons. Results suggest that the features of the PD program had a positive effect on teachers' classroom practices regarding the use of graphs.
\end{abstract}

Keywords: professional development, in-service teachers, middle school mathematics, representations, graphs

\section{Introduction}

The demand to enhance the quality and outcomes of teaching and learning in the United States (US) -as in many other countries- has put teacher Professional Development (PD) high on the agenda of policy makers, administrators, educators, and researchers. Given that all states are required to provide in-service teachers with high quality learning opportunities (US Department of Education, 2001), a plethora of PD programs have arisen during the past decades (Garet, Porter, Desimone, Birman, \& Yoon, 2001). In particular, within K-12 mathematics, the National Science Foundation (NSF) has supported the development of numerous rural, urban, and statewide PD programs. This paper draws data from an on-going NSF-funded inter-state project for grades 5-9 mathematics teachers.

Approaches to PD have been extremely varied, both in content and shape. According to researchers in the field (e.g., Darling-Hammond, 2010; Hoekstra \& Korthagen, 2011), a large number of programs have provided no evidence regarding their impact on teachers. In particular, researchers today emphasize the need for more studies focusing on the impact of PD on teachers' instructional practices (Dede et al., 2009; Kazemi \& Hubbard, 2008; Lewis, Perry, \& Murata, 2006). Most research on PD effectiveness has tended to rely on measures such as teachers' test scores in content knowledge assessments, self-reported data (e.g., interviews, questionnaires, surveys collected at course completion), or teachers' analysis of classroom video clips, student interviews, or student written work. However, the impact of PD on teaching practices themselves are often neither analyzed nor discussed. This lack is not surprising if we consider that resources and funding for PD research and evaluation are generally limited (Wise, Spiegel, \& Bruning, 1999).

The present study contributes to fill this gap in the PD literature. We draw from a large dataset of videotaped lessons and written lesson plans collected at the start and end of an 18-month long PD program. Our analysis focuses on a specific aspect of mathematics teachers' classroom practice: how teachers use graphs in the Cartesian coordinate plane to teach mathematics. This topic is relevant because while many studies have investigated students' difficulties with 
graphs, only a few studies have focused on how teachers use graphs in their classrooms. Further, to the best of our knowledge, there is no prior research on how PD impacts the way teachers use graphs in class to teach mathematics.

In this study, we analyzed all lessons where participating teachers used graphs with no specific prompting at the beginning and end of the PD program. We considered the entire cohort of 56 teachers as a single unit of analysis. The lessons identified by the end of the program presented uses of graphs qualitatively more sophisticated than the beginning lessons (e.g., there were more links between graphs and other representations by the end of the program, teachers made more explicit references to graphs in class and lesson plans). We argue that the shifts might have been promoted by the combination of features of the PD program featured in this study, which are described below. Our overall argument is that PD programs that share these features have the potential to positively impact teachers' classroom practice. This study may therefore inform the design and implementation of other PD programs, both in mathematics and other content areas.

\subsection{Graphs in the Cartesian Coordinate Plane as Tools for Mathematics Teaching and Learning}

This article contributes to the framework of representations as tools for teaching and learning (Brizuela \& Gravel, 2013; Ryken, 2009). We particularly focus on graphs in the Cartesian coordinate plane (from here on, "graphs"), which are amongst the most important forms of representation in mathematics. The Cartesian coordinate plane is also a powerful tool in content areas beyond mathematics, including natural sciences (e.g., physics, biology) and social sciences (e.g., history, psychology).

Instructional programs across the world identify the development of skills for graph interpretation and production as one of the most important objectives of compulsory education (National Council of Teachers of Mathematics [NCTM], 2000; Organization for Economic Co-Operation and Development [OECD], 2006). Mathematics education curricula from grade 5 onwards typically recommend that teachers engage students in using graphs to tackle a variety of situations, for example to find the solutions to word problems, to summarize datasets, to interpret relationships between variables, to examine and/or infer patterns, and to model situations.

Given the importance of visualization in mathematics, graphs are powerful because they allow students to visualize mathematical concepts (Battista \& Clements, 1991). From this viewpoint, graphs are similar to other representations such as pictures, images, and diagrams. However, graphs are even more powerful because they can also provide students with visual representations of mathematical relations, functions, and their properties. According to Leinhardt, Zaslavsky, and Stein (1990), the introduction of graphs represents an important landmark in the middle school mathematics curriculum. Using graphs to represent functions constitutes "one of the earliest points in mathematics at which a student uses one symbolic system to expand and understand another (e.g., algebraic functions and their graphs, data patterns and their graphs, etc.)" (p. 2).

Most prior studies on graphs have focused on the difficulties students encounter when interpreting and/or producing function graphs (see review by Leinhardt et al., 1990). For example, students tend to interpret time/distance graphs as descriptions of the shape of the terrain walked (Kerslake, 1981) and focus on isolated points instead of focusing on intervals, the shape of the graph, and the functional relationship between two variables (Bell \& Janvier, 1981). Additionally, students often fail to relate the shape of the graph of a function to its symbolic-algebraic representation. Such difficulties might be partially due to students' limited experience with function graphs, which tend to be introduced rather late in the curriculum (commonly no earlier than in $6^{\text {th }}$ grade) and dissociated from the teaching of algebra as rules for solving equations (Yerushalmy \& Schwartz, 1993). Before that, students' experiences with graphical representations are limited to bar or pie graphs. Moreover, when function graphs finally appear in the curriculum, emphasis is placed on learning how to plot points in the Cartesian space and on interpreting what the points represent (Bell \& Janvier, 1981). Other aspects that may contribute to students' difficulties is the dissociation between the teaching of linear and non-linear functions and the fact that graphs are oftentimes taught as independent units and in isolation from other forms of representation (Stylianou, 2010).

Teaching about graphs should go beyond how to plot points and be integrated with other mathematical contents. Alternative approaches to the teaching and learning of algebra (e.g. Schwartz \& Yerushalmy, 1992; Yerushalmy \& Schwartz, 1993) call for a functions approach to algebra, where, instead of starting by learning how to compute solutions to equations using the syntactic rules of algebra, students start by learning about function graphs. Equations are then conceived as comparisons between two functions. Switching from a traditional approach to a functions approach to algebra requires the preparation of teachers, as well as evaluating how this preparation may influence their classroom practice. In our review of the literature, we have found very few studies on how mathematics teachers use graphs to teach mathematics and no studies on how PD impacts the way teachers use graphs in class, which is the focus of the present paper.

Using multiple representations in a flexible and inter-related manner has the potential to help students develop deeper 
understanding of mathematical concepts and relationships (Kaput, 1987, 1998; Ryken, 2009). However, recent research shows that depending on how representations are introduced and utilized by teachers, they may or may not be helpful in facilitating students' learning (Chapman, 2010). In the same vein, the study conducted by Duncan (2010) shows that teachers across countries oftentimes fail to place sufficient emphasis on the links between the representations used, which tends to result in students' lack of relational understanding of the topics and their related concepts.

It therefore seems essential for teachers to be strategic in how they work with multiple representations in class and how they establish relationships among them. However, according to Stylianou (2010), "there is little evidence that either professional development programs or teacher preparation programs have been preparing teachers and prospective teachers to meet these demands and integrate them in instruction successfully" (p. 326). This justifies the need for PD programs that focus on multiple representations and on the integrations of algebra and functions.

\subsection{Common Features of High-Quality PD Programs: Context for the Research}

Researchers in different content areas have identified a series of common features in what they call high-quality PD programs (e.g., Borko, 2004; Desimone, 2009; Higgins \& Parsons, 2009; Garet et al., 2001; Goldsmith, Doerr, \& Lewis, 2014; Kazemi \& Hubbard, 2008). High-quality PD programs provide teachers with:

- Deeper understanding of the subject matter they teach and of how students think of and learn the subject matter;

- Multiple opportunities to engage in exploration, reflection, and discussion;

- Activities that involve attending and responding to student thinking;

- Constructive and non-prescriptive feedback on tasks teachers perceive as relevant;

- Contexts for collegial sharing, collaboration, and follow-up support during extended periods of time.

In the field of mathematics education, examples of PD programs extensively cited for their success in promoting positive changes in both teachers and students are "Cognitively Guided Instruction" (CGI) (Carpenter et al., 1989), "Integrating Mathematics Assessment" (IMA) (Saxe, Gearhart, \& Nasir, 2001), and "Developing Mathematical Ideas" (DMI) (Bell, Wilson, Higgins, \& McCoach, 2010). These programs used different measures to document their impact such as teachers' and students' procedural and conceptual understandings and performance in standardized assessments, classroom observations, satisfaction surveys, and teacher and student interviews. We consider all these measures to be important, and in fact, we have collected similar measures in our PD program. However, given current urgent calls for more studies on instructional practices, we decided to focus the present paper on classroom data (videotaped lessons and lesson plans).

The five features mentioned above guided the design and implementation of our PD program for grades 5-9 mathematics teachers, "The Poincaré Institute for Mathematics Education" (for details, see Teixidor-i-Bigas, Schliemann, \& Carraher, 2013). In the following subsections, we explain how the Poincare Institute meets the five features of high quality PD programs mentioned above. Each of the features allows us to describe particular aspects of our program in terms of its content, structure, goals, approach, and working dynamics based on the curriculum delivered to the first cohort of participating teachers from January 2011 to June 2012.

1.2.1 Helping Teachers to Develop a Deeper Understanding of the Subject Matter They Teach and of How Students Think of and Learn the Subject Matter

With the final goal of improving students mathematical learning, the Poincaré Institute aims at helping grades 5-9 mathematics teachers deepen and broaden their understanding of middle school mathematics, as well as their understanding of how students at these levels think of and learn mathematics. The educational backgrounds of these teachers vary widely, as the licensing requirements have shifted over the years. Thus, whereas some teachers have strong backgrounds in mathematics, others have no formal training in mathematics at all. To provide all our participants with a common ground, this PD program offers a multidisciplinary investigation framework designed to help teachers re-envision the mathematics they are most commonly required to teach (Common Core State Standards Initiative [CCSSI], 2010; NCTM, 2000).

The first cohort of teachers took a series of three graduate level semester-long courses. The courses -Representations (Course 1), Transformations (Course 2), and Invariance and Change (Course 3)- focused on mathematical content knowledge and students' mathematical thinking and learning. Three core ideas pervaded the content of the three courses:

Functions. Numerous researchers in mathematics education have argued for decades that functions have the potential to unify and give more coherence and depth to the entire K-12 mathematics curriculum (Schliemann, Carraher, \& Brizuela, 2007; Kaput, 1987, 1998; Schwartz \& Yerushalmy, 1992). Functions allow the integration of topics such as the operations of arithmetic, fractions, ratio and proportion, geometry, 
generalization, modeling (data fitting), and algebra. These researchers have therefore proposed that functions and algebra should pervade the curriculum instead of abruptly appearing in high school. Our PD program reflects this line of thought. In the courses, teachers learned about functions and explored their applications, analyzed evidence showing how functions and their representations can be used for the teaching of K-12 mathematics (including elementary mathematics), and explored students' intuitive ideas about functions.

Multiple representations. Research indicates that using multiple representations in a flexible and interrelated manner, establishing connections among representations and translating between and within them, is key to constructing broad and deep mathematical understandings (Ryken, 2009; Teixidor-i-Bigas et al., 2013). This idea implicitly pervaded our curriculum. In the PD courses, teachers were provided with a wealth of representations for their own mathematical learning (symbolic notation, graphical, tabular, pictorial, verbal, etc.), and were shown how students' learning is significantly richer when multiple representations are carefully introduced, analyzed, and discussed. Moreover, teachers were encouraged to express their own mathematical ideas through multiple representations.

Modeling and applications. The importance of exploring the connections between mathematics, science, and the "real world" was also emphasized in our courses. We oftentimes asked teachers to tackle modeling situations and applied problems involving quantities (e.g., weight, cost, area, length, time). In addition, we asked them to explore students' thinking about open-ended problems. These kinds of extra-mathematical situations raise crucial issues about the similarities and differences between mathematics and everyday life (Blum, 2002).

All topics addressed in the three courses taken by the teachers were unified under these core ideas. Specifically, we covered topics such as numbers (fractions, rational numbers, integers, divisibility), arithmetic (the basic operations of addition, subtraction, multiplication, and division), and algebra (functions, equations, slopes, and solutions of linear and polynomial equations).

\subsubsection{Providing Teachers with Multiple Opportunities to Engage in Exploration, Reflection, and Discussion}

The three courses were delivered in a highly interactive "hybrid" environment in which facilitators and teachers had both online and face-to-face interactions. We asked teachers to engage -both collectively and individually- in the solution of open-ended mathematical and science problems as well as in activities related to mathematical thinking, learning, and teaching. By open-ended we mean that multiple solutions and/or solution methods could be applied and accepted as valid. Problems and activities generally tackled real-life situations, and aimed to be as challenging and engaging as possible.

Teachers were asked to complete assignments every week. Course assignments varied in content and form (examples are given in the subsections below). We provided teachers with materials such as written notes, mini-lecture videos to clarify and/or further elaborate on ideas explained in the notes (recorded by specialists in mathematics, science, and/or education), applications designed to explore the topics at hand, challenge questions to be solved and discussed, selected video clips from mathematics classrooms, samples of students' work, excerpts from book chapters and research articles, and excerpts from interviews with students. All these materials were used to promote teachers' investigation and collaborative discussion. We provided teachers with an online forum site where they commented on other teachers' work, asked questions, responded to the facilitators' feedback, and shared ideas for future submissions.

\subsubsection{Engaging Teachers in Activities That Involve Attending and Responding to Student Thinking}

Teachers were particularly drawn to the "education weeks," in which we engaged them in activities that involve attending and responding to student thinking (e.g., Jacobs, Lamb, \& Phillipp, 2010), such as analyzing student written work and classroom videos, interviewing students (individually or in small groups), and designing, implementing, and analyzing learning activities. The goal of these learning activities was to address specific aspects of student thinking that had been identified in the interviews. Each teacher videotaped the implementation of his/her learning activity and analyzed, in a written individual report, his/her teaching as well as students' learning. All reports were posted online, along with selected classroom video clips, and were discussed by the group facilitators and other fellow teachers.

\subsubsection{Providing Constructive and Non-Prescriptive Feedback on Tasks Teachers Perceive as Relevant}

Given the large number of participants, teachers were divided into teams of about six teachers each. Two facilitators, generally one educator and one mathematician or physicist, worked with each team. Among other responsibilities, facilitators provided constructive feedback and suggested questions to prompt further discussion and reflection among teachers. As explained below, we also encouraged and gave teachers support to build their own professional learning communities, where they could potentially receive feedback from their own colleagues and peers. 
Our general approach in our work with the teachers was not prescriptive (or directive). We strongly believe that fostering teachers' reflection and discussion is the most beneficial strategy to promote their learning. We therefore did not provide teachers with prescriptive/corrective feedback, or with "pre-packaged" lessons for them to implement directly in the classroom. Similarly, we did not explicitly tell teachers how the mathematical problems posed should be solved, nor provided them with rigid descriptions of how students think and learn mathematics. And most importantly, we did not tell teachers how they should teach their students. Instead, we fostered teachers' reflection and discussion as a way to promote their learning. The kind of feedback we gave to teachers was aimed at guiding them to observe unexplored aspects and to raise new questions and ideas.

\subsubsection{Providing Teachers with Contexts for Collegial Sharing, Collaboration, and Follow-up Support during Extended} Periods of Time

In our courses, teachers were encouraged to make use of the online forums, where they could post questions and new ideas, and discuss any topic related to mathematics or classroom practice with other fellow teachers and with the course facilitators. During Course 1, for example, all assignments were divided into two phases. In the first phase, once teachers completed reading/viewing certain materials, we asked them to answer a set of open-ended questions aimed at promoting exploration and collaboration. Course facilitators provided teachers with constructive feedback on their responses, and gave them the opportunity to review and comment on the work of their peers. In the second phase, new materials were provided (generally videotapes of classroom episodes, samples of students' work, readings and notes containing the views of specialists, research articles, etc.). Based on these materials, we asked teachers a new set of open-ended questions aimed at helping them revise or reflect further upon the answers they gave to the set of questions asked in the first phase.

Facilitators also held monthly face-to-face meetings with teachers to support their learning. The goal of the meetings with course facilitators was for teachers to express their concerns and suggestions, and also for us to follow up on their progress. Teachers met weekly on their own to collaboratively discuss issues related to mathematics education. They were given freedom to choose what they wanted to discuss at their meetings, as long as the topics were related to mathematics and its teaching in their classrooms.

\subsection{The Use of Graphs in the Poincaré Institute}

Graphs played an important role in the Poincare Institute, being one of the representations most frequently used with the teachers in our courses. Perhaps as a consequence of the way mathematics is generally taught, at the start of the PD courses, many teachers brought an understanding of mathematics and algebra primarily based on symbolic-algebraic notation and equation solutions. This was particularly common among teachers with strong mathematics backgrounds. In our viewpoint, such an understanding is partial and limited because symbolic-algebraic notation does not capture the entire complexity of mathematical ideas (Rico, 2009). Graphs therefore allowed us to help teachers "visualize" the mathematics they knew.

In discussing how to analyze relations between sets of numbers, teachers in our program were encouraged to use multiple representations for functions, such as verbal statements, number lines, data tables, symbolic notation, and of course graphs. Their work on equations within a functions approach to algebra helped them consider equations as a relation between two functions, each having a domain and a codomain, considering the solution(s) to the equation as the value(s) that satisfies the equation. Other values would falsify the equation. Teachers also examined and discussed how syntactic transformations of the equation corresponded to transformations of the graphs of the two functions in the Cartesian space.

In our program, we provided teachers with a variety of graphical representations to foster their own learning (not only graphs on the Cartesian coordinate plane but also number lines, bar graphs, and other models such as "pizza" models, "length" models, etc.). In addition, we oftentimes encouraged teachers to express their mathematical ideas through graphs in the course assignments, and asked them to establish links among graphs and other representations, as well as analyze the strengths and weaknesses of different representations. Finally, we provided teachers with opportunities to explore how graphs allow us to probe students' mathematical thinking and promote their learning. According to our non-prescriptive approach to PD, however, we never explicitly told teachers that they should use graphs and other representations, neither for their own learning nor in class. This idea is key to understanding the significance of the results presented in this paper.

\section{Purpose}

In this study, we analyzed how Cartesian graphs were included in mathematics lessons taught by grades 5-9 mathematics teachers before or after participating in a PD program. The purpose of the paper is to provide evidence that certain features of PD programs, when combined, have the potential to positively affect teachers' instructional practices. Our 
main research question is: What are some of the characteristics that can be identified in mathematics teachers' classroom practices, specifically in relation to the use of graphs, before and after participation in a -presumably high quality- PD program focused on mathematics and student mathematical thinking?

We present a detailed analysis of all lessons where teachers chose to use graphs in class with no specific prompting, at the start or at the end of the PD program. Note that we utilize the word "use" here in a broad sense, including lessons where, for example, teachers implemented activities involving graphs, or asked students to interpret or produce graphs during class, or lessons where the teacher him/herself drew graphs on the board to explain a certain mathematical concept, even if the explanation was not planned ahead. The results are illustrated with classroom dialogues, excerpts from lesson plans, and activities/materials used by the teachers in class.

\section{Overall Data Collection Rationale}

\subsection{Participants in the PD Program}

The cohort of participating teachers was composed of 56 grades 5-9 mathematics teachers (49 females and 7 males), who taught in schools located in distant geographical areas across three states in the US. Their ages ranged from 26 to 63 years, and their experience as mathematics teachers ranged from 2 months to 28 years. The teachers had a variety of educational backgrounds, holding undergraduate and/or master's degrees in Mathematics (13 teachers), Mathematics Education ( 8 teachers), in disciplines related to Natural Sciences and Technology (8 teachers), and in Social Sciences and Humanities (27 teachers). In this study, we analyzed all lessons where teachers used graphs in class at the start of the PD program (lessons by 7 teachers) and at the end (lessons by 5 teachers).

\subsection{Data Collection Procedure}

One of the main research goals of our PD program was to examine the impact of our three courses on how teachers were actually teaching their regular mathematics curriculum. To that goal, we collected a wealth of classroom data at the four times shown in Table 1.

Table 1. Data collection overview

\begin{tabular}{cc}
\hline Time point during PD program & Month / Year \\
\hline Start of Course 1 & January 2011 \\
End of Course 1 & May 2011 \\
End of Course 2 & December 2011 \\
End of Course 3 & June 2012 \\
\hline
\end{tabular}

We were interested in capturing teachers' spontaneous instructional approaches while implementing their regular curriculum. In other words, we wanted to keep the teaching conditions as "natural" as possible. Consequently, we gave teachers no specific guidelines regarding lesson content or format when we filmed them. We hence videotaped classes dealing with different mathematical topics (e.g., algebra, geometry, data analysis) and implemented through different classroom formats (lectures, work in small groups, individual work, and combinations of these formats). We also asked teachers to share the lesson plans they designed when preparing the lessons we videotaped.

When we launched the program, we informed all 56 participating teachers -both verbally and in writing-about the data collection timeframe and encouraged them to collaborate with us. We made clear that participation was voluntary and not a requirement for course completion. A teacher could therefore decide never to be videotaped, or agree to be videotaped once, twice, three, or four times. Videotaping sessions were scheduled based on teachers' availability and preferences. We videotaped entire classroom periods using two video cameras (one following the teacher, the other focused on the students).

\subsection{Data Sources and Analysis}

Out of the 56 participants, 44 teachers were videotaped at least at one moment in our data collection. We videotaped 147 classroom periods in total. Table 2 shows the distribution of teachers by time (rows) and grade level (columns). The total number of different teachers videotaped from each grade level is indicated in the first row of the table (see $N$ values). Numbers in the columns (teachers according to grade level) cannot be added because the same teacher could have participated in several videotaping sessions.

The analysis presented below is focused on the lessons that involved the use of graphs at the start and end of the PD courses. This decision was made based on practical constraints (i.e., space limitations), and most importantly, on analytical reasons (i.e., differences in how teachers' used graphs could be attributable to the effect of participating in the PD program). After multiple viewing/reading of the data, the authors produced a set of descriptive codes in order to account for the presence/absence of different features and behaviors. All videos and lesson plans were independently analyzed by two of the authors. Disagreements were solved through discussion. 
Table 2. Teachers videotaped by time (rows) and grade level (columns)*

\begin{tabular}{ccccccc}
\hline Times & $\begin{array}{c}5^{\text {th }} \text { Grade } \\
(N=4)\end{array}$ & $\begin{array}{c}6^{\text {th }} \text { Grade } \\
(N=10)\end{array}$ & $\begin{array}{c}7^{\text {th }} \text { Grade } \\
(N=11)\end{array}$ & $\begin{array}{c}8^{\text {th }} \text { Grade } \\
(N=14)\end{array}$ & $\begin{array}{c}9^{\text {th }} \text { Grade } \\
(N=5)\end{array}$ & $\begin{array}{c}\text { TOTAL } \\
(\text { N=44 })\end{array}$ \\
\hline Start of Course 1 & 4 & 8 & 7 & 11 & 5 & 35 \\
End of Course 1 & 3 & 6 & 4 & 8 & 1 & 22 \\
End of Course 2 & 2 & 8 & 7 & 8 & 0 & 25 \\
End of Course 3 & 3 & 4 & 3 & 5 & 0 & 15 \\
\hline
\end{tabular}

* Numbers in the same column cannot be added. Each $N$ indicates total number of teachers videotaped in each grade level. Notice that no $9^{\text {th }}$ grade teacher was videotaped at the End of Courses 2 and 3.

\section{Results}

This section is divided into five sub-sections, with headings that convey the essence of the main findings of the study. All teachers' names are pseudonymous.

\subsection{Towards More Frequent Use of Graphs, Even at Earlier Grade Levels}

Of the 35 teachers videotaped at the start of the program, seven teachers $(20 \%)$ used graphs-including one $7^{\text {th }}$ grade teacher, three $8^{\text {th }}$ grade teachers, and three $9^{\text {th }}$ grade teachers. In contrast, of the 15 teachers videotaped at the end of the program, five teachers $(33 \%)$ used graphs - including two $6^{\text {th }}$ grade teachers, one $7^{\text {th }}$ grade teacher, and two $8^{\text {th }}$ grade teachers. As shown in Table 2 , no $9^{\text {th }}$ grade teachers volunteered to participate in this last videotaping session.

These data reveal two interesting results. First, the relative percentage of teachers who used graphs was $13 \%$ higher by the end of the PD program than at the beginning. This suggests that participation in this PD program fostered more frequent use of graphs among the teachers. Second, participation in the PD seems to have fostered the use of graphs at earlier grade levels. At the beginning of the PD courses, graphs were only used from $7^{\text {th }}$ grade on, and most frequently in $8^{\text {th }}$ and $9^{\text {th }}$ grades, while, at the end of the program, two $6^{\text {th }}$ grade teachers included graphs in their lessons. Although we videotaped some $5^{\text {th }}$ grade teachers in both beginning and end of our program (see Table 2), none used graphs in the lessons we observed, which is surprising because most of these lessons tackled topics where graphs would have been helpful for students to better understand the material.

\subsection{Towards a More Salient Presence of Graphs in the Lesson Plans}

The second aspect we examined concerned the lesson plans. As argued by Hoekstra and Korthagen (2011), lesson plans provide valuable information about teachers' cognition, in particular about their teaching priorities, intentions, and goals. In our analysis, we attempted to answer the following questions: Did teachers refer to graphs at all in their lesson plans? If so, how? Were there differences in the ways teachers talked about graphs at the beginning and at the end of the PD program?

Lesson plans gathered at the start of the courses presented no explicit references regarding why or how graphs would help students learn the mathematical content at hand. A few lesson plans did present activities that required students to produce or interpret graphs. However, teachers provided no contextualization or justification for the use of graphs. For example, Mary $\left(9^{\text {th }}\right.$ grade teacher) inserted the textbook activity shown in Figure 1 into her lesson plan. The activity asked the students to find the equations corresponding to three given graphs expressed in point slope form. She provided no written explanation or justification about the role that the given graphical representations would play in students' mathematical thinking and learning.

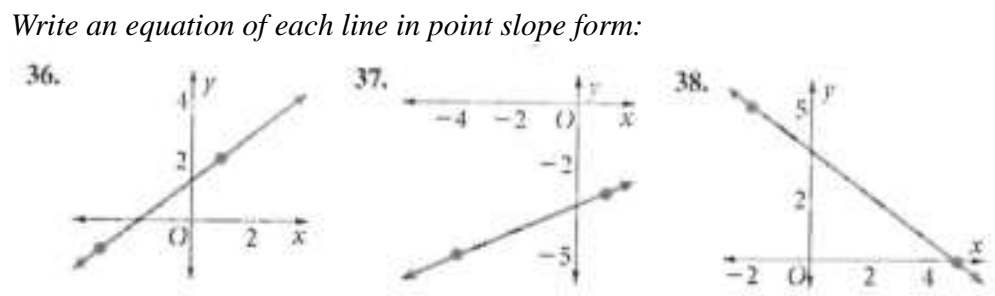

Figure 1. Excerpt from Mary's lesson plan ( $9^{\text {th }}$ grade $)$

The results at the end of PD were substantially different. The lesson plans of four out of the five teachers who used graphs contained explicit references to the vital role that graphs would play in fostering students' learning about the mathematical topics addressed in that specific lesson. This represents a considerable increase with respect to the beginning of the program, when no teacher provided explanations of this nature. For example, $8^{\text {th }}$ grade teacher Annette designed a modeling activity focused on a situation involving an exponential relationship between two variables. In her lesson plan, she provided a detailed rationale of the most common difficulties students have when trying to understand the relationships between two variables and, more specifically, when interpreting and producing their corresponding 
graphs. In the excerpt shown in Figure 2, Annette started by characterizing graphs as tools that "tell(s) a story."

- $\quad$ Students know that the graph tells a story. However, they at times have difficulty telling the story. This activity will hopefully improve their ability to read and interpret what they are seeing. It will also hopefully improve their ability to read the scale on a graph and interpret what the values mean.

- Some of the misunderstandings that students have regarding graphing include: not seeing a relationship between all values on the graph, having multiple explanations for a single graph, i.e. not seeing the whole picture so that a story relates to all points on the graph, and being able to explain what is happening from one point to another (what kind of change is happening.) When creating graphs, students have difficulty deciding on a scale and scale intervals. They also think that they must use the same scale on the $x$ and $y$-axes.

- It would be helpful to have a better understanding of how students make connections between two variables that have a relationship and also how they "attack" a graph. When they look at a graph, where do they look first, what information do they see, do they look at the axes, etc.? How do they process this information to come up with a conclusion?

Figure 2. Excerpt from Annette's lesson plan $\left(8^{\text {th }}\right.$ grade $)$

Furthermore, the lesson plans collected at the end of the program were very explicit regarding the goals of using graphs in class. For example, $6^{\text {th }}$ grade teacher Gabriella designed a lesson intended to introduce students to the Cartesian space. In the following excerpt (Figure 3), she presented the specific mathematical concepts she was planning to teach her students through graphs, and mentioned some specific actions aimed at exploring the coordinate plane.

\section{Lesson Objectives:}

- To introduce students to the four quadrants of the coordinate plane

- To review coordinate plane vocabulary: $x$-axis, $y$-axis, origin, quadrant, coordinate

- To practice graphing and identifying points on the coordinate plane

Figure 3. Excerpt from Gabriella's lesson plan ( $6^{\text {th }}$ grade $)$

These findings suggest that participating in the PD program helped teachers increase their awareness of the importance of graphs in mathematics teaching, and helped them articulate deep justifications of the learning that might occur in students as a result of using graphs.

\subsection{Towards More Explicit Classroom Talk Regarding the Goals of Using Graphs}

We also found an interesting shift in teachers' classroom talk regarding graphs. Our guiding questions here were: Do teachers explicitly refer to the goals of using graphs in class? Do they provide students with explanations, justifications, or any other sort of context about why using graphs is helpful or important?

Interestingly, the findings are consistent with the ones described in the previous subsection. None of the seven teachers who used graphs at the beginning of the program produced the kind of explanations we were seeking. Although these teachers asked students to complete activities (in class and/or as homework) that involved the use of graphs, the goals of utilizing graphs were not explicitly referred to. The only exception was found in a class taught by Lisa, a $9^{\text {th }}$ grade teacher. The lesson, procedural in nature, dealt with the conversion of equations into different symbolic-algebraic forms. As can be observed in the excerpt below, the teacher implicitly referred to one of the benefits of using graphical representations.

Excerpt of Lisa's classroom $\left(9^{\text {th }}\right.$ grade $)$

Teacher: $\quad$ Now that we have the vertex, we need to graph, right? Okay? So, in addition to knowing the vertex by looking at this ((points to the vertex of the parabola)), I can actually see how the graph is shifting. This is called a transformation. Have you guys done that in Algebra before? Each number represents doing something to the graph. So, our very original, simple graph would be just the original parabola. So, if you think of the parabola, this is the vertex right? From this vertex [...] ((the teacher continues to make calculations for several data values)) What do you think that does to the graph? Where do you think it moves it? [...] This affects the y-value.

What Lisa did and said in this episode conveyed the idea that graphing is helpful because it allows us to observe the consequences of changing the parameters of symbolic-algebraic expressions. This idea, however, was not explicitly articulated in her classroom talk. This case was the only instance identified at the start of the program. 
In contrast, four out of the five teachers who used graphs at the end of the program articulated explicit references to the goals of using graphs in class. This percentage represents, once again, a considerable increase compared to the beginning of the program. For example, this is how Gabriella (the $6^{\text {th }}$ grade teacher featured in the prior subsection) presented the introductory lesson she designed on the Cartesian space to her students. As can be observed, she explicitly highlighted the importance of graphs to model and graphically visualize function lines.

Gabriella's introduction to the lesson $\left(6^{\text {th }}\right.$ grade $)$

Teacher: We are going to do a couple of fun activities with the coordinate plane. How many people have heard of the coordinate plane before? Raise your hand if you can tell me what is one thing you know about the coordinate plane. ((Some students share their ideas. There is some whole-group discussion for a while)). Coordinate planes are important because we can see how lines are modeled [...] ((The teacher writes down a function table on the board and asks students what that is)). With this function table we could graph these coordinates on the coordinate plane, and see them graphed, right?

Teacher Zeus $\left(8^{\text {th }}\right.$ grade teacher) designed a lesson on graphing. While presenting the goals of the lesson, he explained that graphs allow us to analyze the connections between different variables and to identify existing patterns.

Zeus's introduction to the lesson $\left(8^{\text {th }}\right.$ grade)

Teacher: $\quad$ The focus of class today is going to be on scatter plots. [...] Oftentimes, scientists, mathematicians, and people are just looking at data, want to look for connections between two things, whether it time and distance, or maybe is between how tall somebody is and how far they can jump. So, by graphing two different things in the $\mathrm{X}$ - and $\mathrm{Y}$-axis we can look for patterns in the appearance of the graph.

\subsection{Towards More Use of Graphs in Modeling and Application Problems}

The fourth area where we identified differences between the beginning and end of the PD dealt with the kind of mathematical activities in which graphs were used. It is worth mentioning that most activities that included graphs at the start of the program were taken from textbooks, whereas those used at the end were designed by the teachers themselves. It might be the case that teachers were not entirely satisfied with how graphs were treated in the textbook activities, feeling therefore the need for designing new activities or modifying existing ones.

Most teachers who used graphs at the beginning of the program (five out of seven teachers) exclusively implemented activities that had a single correct answer (or "closed" activities). These activities could be solved using simple solution processes, such as plotting a set of pre-determined data points on grid paper and drawing function lines, decoding specific aspects of given graphs (e.g., "What is the $y$-intercept of this line?"), or finding the equations corresponding to given graphs. More sophisticated processes such as predicting, finding patterns, generalizing, or modeling were infrequent.

An example of a closed mathematical activity comes from the class taught by Mary, the $9^{\text {th }}$ grade teacher featured earlier. She implemented a textbook activity that involved graphing given equations in graphing paper where the axes where both given and labeled (Figure 4). There was, therefore, a single way to respond correctly to this activity. The final goal was for students to observe the behavior of the lines as the parameters of the symbolic-algebraic expressions changed.

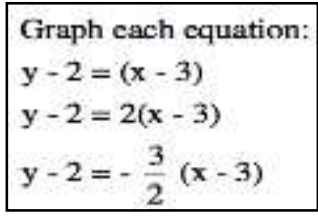

Figure 4. Another textbook activity implemented by Mary $\left(9^{\text {th }}\right.$ grade $)$

The results at the end of the PD program were quite different. Most teachers who used graphs in their classes (four out of five) implemented modeling and application activities. The activities could be potentially solved through multiple solution methods and had multiple valid answers (i.e., "open-ended" activities). The processes required to complete them went far beyond the rote procedures involved in the activities posed at the start of the program. Here, graphs were used to represent and examine real world and science situations, to predict and estimate unknown values and/or quantities, as well as to find patterns and generalize.

The modeling activity designed and implemented by Pearl $\left(8^{\text {th }}\right.$ grade teacher) is an illustrative example of an open-ended activity. Its goal was to foster students' understanding of linear equations. Figure 5 shows an excerpt of the lesson plan Pearl submitted. She asked students to collect and register their own empirical data on a table (in particular, 
the number of pennies that a plastic cup supported by spaghetti could hold); then, she asked students to graph the results and draw the line of best fit in order to make predictions; students were then asked to translate the information into other representations (symbolic notation, verbal); and finally, Pearl asked students to explore the connections between these representations. This activity, therefore, required students to use graphs in a complex manner, and more generally, to use mathematics to understand a real life scenario.

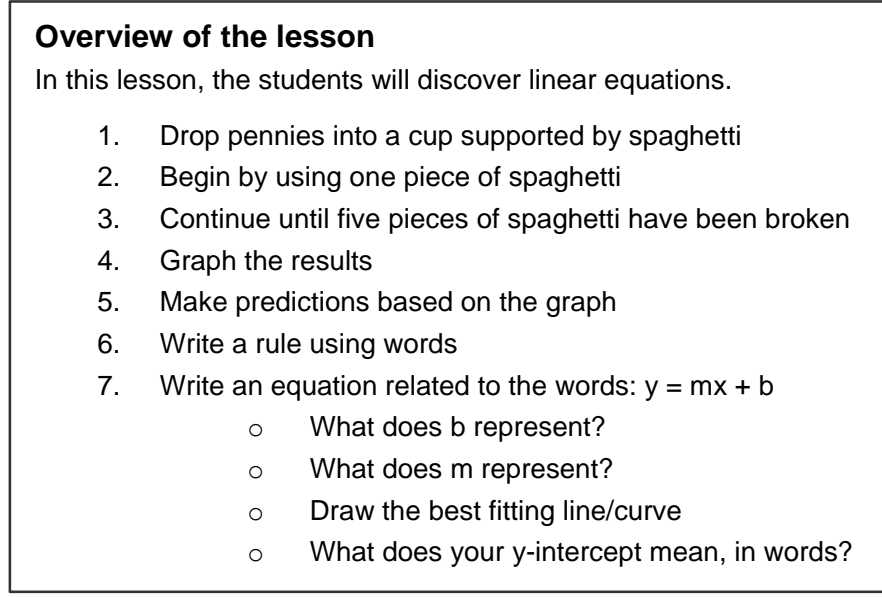

Figure 5. Modeling activity used by Pearl $\left(8^{\text {th }}\right.$ grade $)$

\subsection{Towards More Connections between Graphs and Other Representations}

The final area where we found differences between the start and end of the courses concerned the connections between graphs and other representations. Our working questions were: How do teachers present and use graphs in the classroom? Do they treat them in isolation or in connection with other representations? How are connections between different representations established?

Graphs played a non-central role in the lessons videotaped at the start of the program. In the classes taught by five out of the seven teachers, graphs were used only once during the lesson, generally very briefly, with the goal of illustrating ideas previously explained using symbolic-algebraic notation. The excerpt presented above from Lisa's class $\left(9^{\text {th }}\right.$ grade) illustrates these points. A similar case is Karen's, an $8^{\text {th }}$ grade teacher. The lesson she taught was also focused on converting equations into different symbolic forms. As shown in the excerpt below, Karen used a graph in response to the question asked by a student (Olivia). The teacher's goal was to graphically illustrate the notion of slope, which she had previously explained from a symbolic-algebraic perspective. After answering student Olivia's question, Karen continued her lesson as planned, focusing exclusively on symbolic-algebraic notation. Graphs were not used again during the lesson.

Episode from Karen's class $\left(8^{\text {th }}\right.$ grade $)$

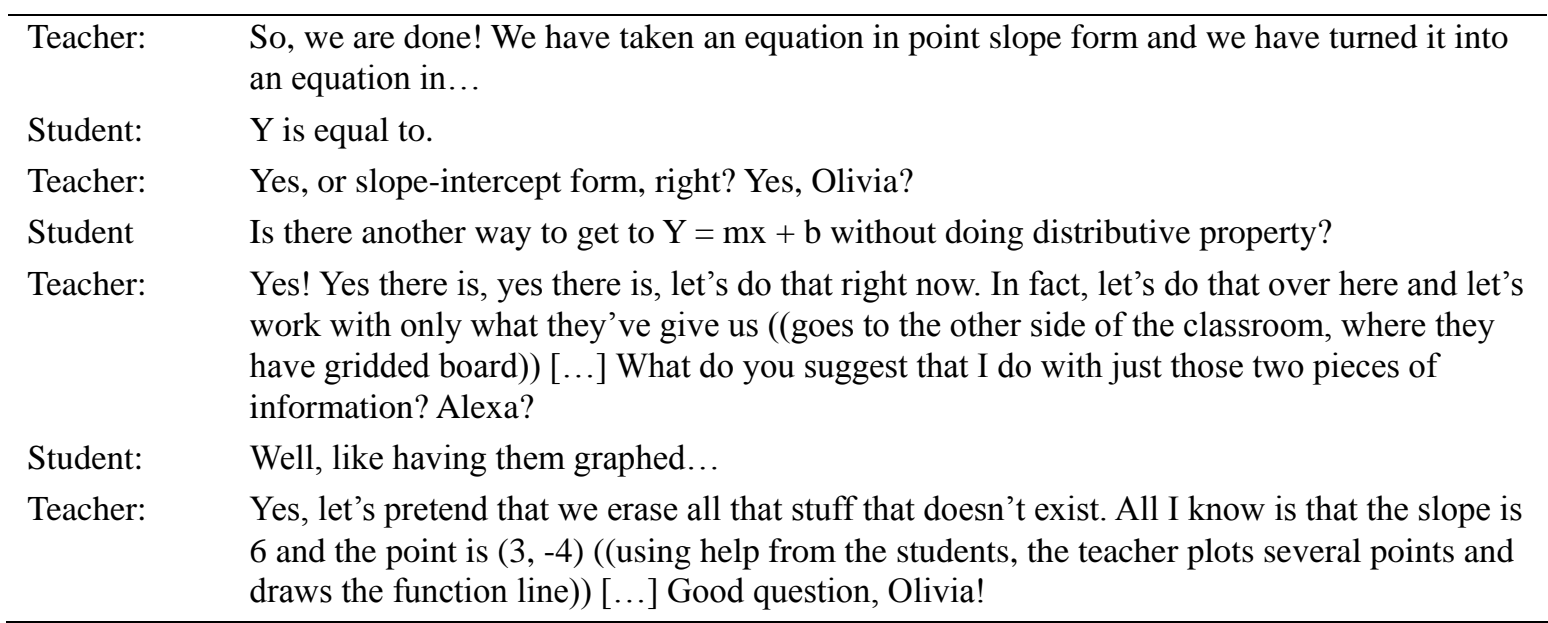

The most common form of representation with which graphs were connected at the start of the program was symbolic-algebraic notation (six out of seven teachers), and tabular to a lesser extent (five teachers). The lesson implemented by Carol ( $8^{\text {th }}$ grade $)$ made use of these three representations in a consecutive fashion: tabular graphical symbolic-algebraic notation (see Figure 6). The final goal was the identification of the equation $y=x+3$, which during 
class seemed to be presented as the most general and complete mathematical representation. The table and the graph were just used as an intermediate step, or in other words, as representational means that could assist the students in determining the equation.

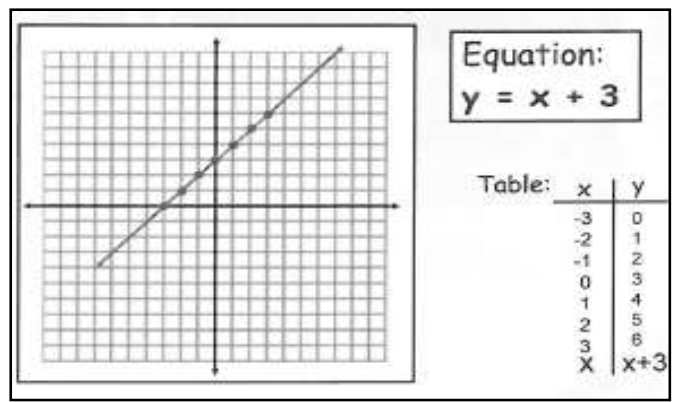

Figure 6. Slide presented by Carol $\left(8^{\text {th }}\right.$ grade)

In contrast, all five lessons videotaped at the end of the program presented a much more interactive use of graphs. That is, graphs were repeatedly utilized during the lessons, establishing a continuous back-and-forth with other forms of representation -especially with tabular, numerical (e.g., ordered pairs, arrow diagrams), linguistic-written representations, and symbolic-algebraic notation. Unlike the lessons at the start of the program, symbolic-algebraic notation was not presented as the most valid. The activities teachers designed were focused on promoting students' understanding of mathematical ideas, representations, and relationships, by exploring real-world phenomena. Multiple representations were utilized in an interrelated fashion to help students achieve this goal.

The activity designed and implemented by Brigitte $\left(6^{\text {th }}\right.$ grade $)$, titled "Algebra Walk Activity," nicely exemplifies these aspects (Figure 7). The goals of the activity were to explore multiple representations for linear functions and to make predictions about how representations change when functions are transformed (more specifically, when linear functions are translated and dilated). We present the activity below, as described by Brigitte in her lesson plan.

\section{Algebra Walk Activity}

1. Review function table by writing the following table on the board

\begin{tabular}{|l|l|}
\hline$x$ & $y$ \\
\hline 0 & 2 \\
\hline 1 & 3 \\
\hline 2 & 4 \\
\hline
\end{tabular}

2. Have student's add to the table then write "rule"

3. Share with students that there is a way to represent that rule on the coordinate plane... ask if students have seen a rule like that graphed on a coordinate plane before...

4. Ask for student volunteers to stand on the $x$-axis (as they go to the $x$-axis give them \#'s to stand on such as $0,1,2 \ldots$ )

5. Then have students on the $x$-axis apply the rule to their value

6. Proceed to do this "Algebra Walk" with other rules such as $y=x-2 ; y=2 x ; y=x+1 ; y=x ; y=x-3$.

a. As you are doing this activity ask students to make predictions and share observations about what they see happening RECORD these observations and any conjectures students have

b. Students may want to choose the rule that they are graphing or make suggestions on what to graph next

\section{Figure 7. Excerpt from Brigitte's lesson plan $\left(6^{\text {th }}\right.$ grade $)$}

During class, Brigitte and her students produced a plethora of representations: numerical representations (ordered pairs), tables of values, graphs drawn on the chalkboard, a large "human graph" enacted on the floor of the classroom by students, verbal/written representations, and symbolic-algebraic notation. The guiding and reflective questions asked by the teacher promoted very interesting discussions among students, helping them realize the inter-connections between the different representational means used. For example, at one point in the lesson, the teacher asked some volunteers to "enact" a function line on the classroom floor, which was made out of square floor tiles. The axes of the Cartesian space had been set up earlier. Each student played the role of a point on the graph, holding a piece of cardboard that contained a written ordered pair. Students were provided with a rope to represent the straight function line that connected all the points (i.e., connected the students). The teacher held an interesting discussion with the students, which we interpret as an attempt to highlight the connections between the ordered pairs and the graph, on the one hand, and the table and the symbolic-algebraic expression, on the other hand. The following conversation occurred once the volunteer students 
were aligned on the classroom floor as a linear function.

Episode from Brigitte's class $\left(6^{\text {th }}\right.$ grade $)$

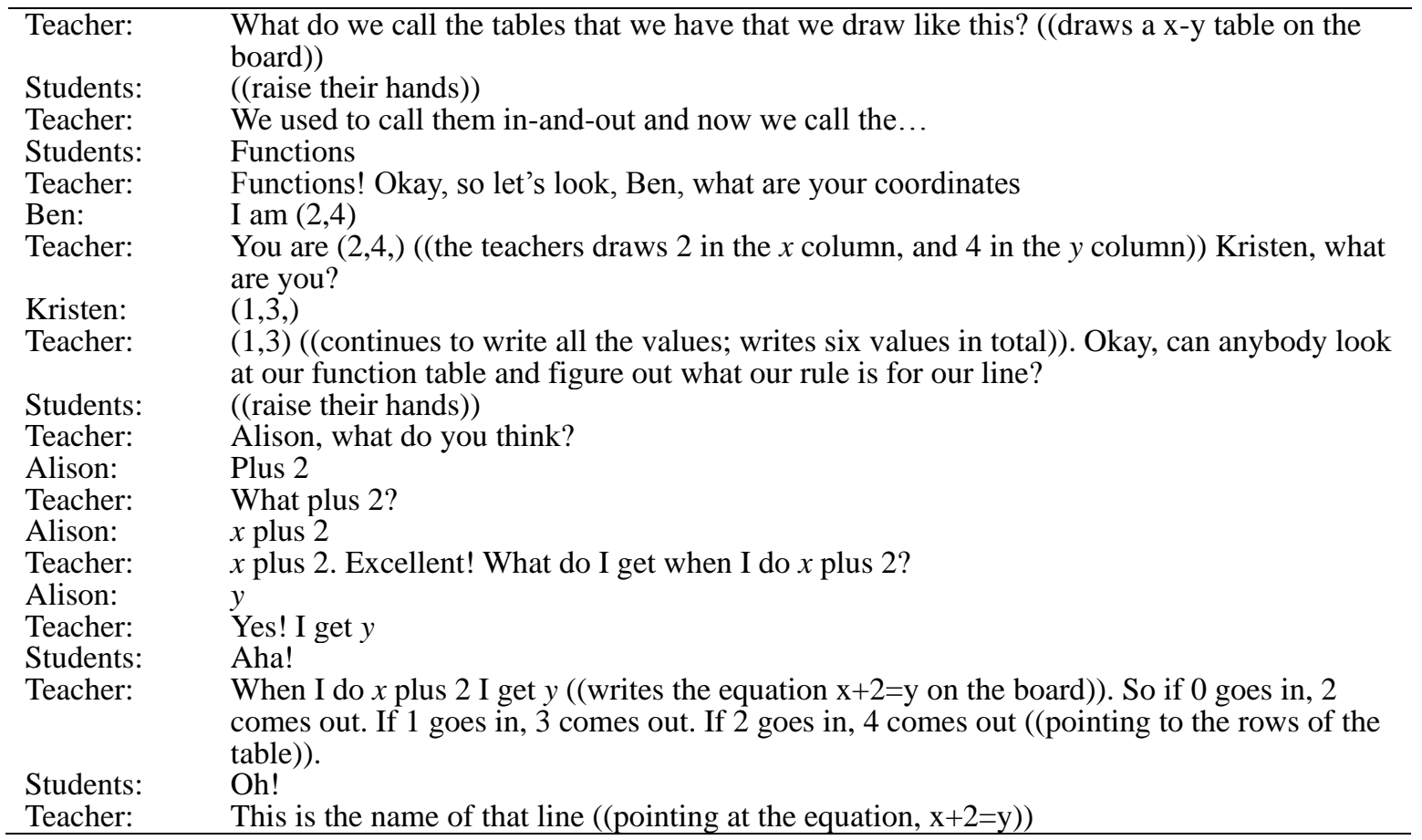

After this conversation, the teacher asked some questions to help students realize that the $y$-value of the ordered pairs the volunteers were holding could be obtained by plugging their corresponding $x$-value into the equation. Students seemed quite surprised once they realized this.

\section{Discussion and Conclusions}

Researchers currently emphasize the need for more empirical studies focused on the impact of PD on teachers' classroom practice (Kazemi \& Hubbard, 2008; Wise et al., 1999). Conducting research on this topic is challenging, as is well known in the field. For example, videotaping teachers' classroom practice at different moments is costly and time consuming (Wise et al., 1999), especially when the number of participants is large and teachers work in distant geographical areas, as in our case. In addition, there are multiple practical constraints that make it highly complicated for researchers to collect classroom data - e.g., schools that do not give approval for videotaping to be undertaken, teachers that prefer not to be videotaped for various reasons, students that do not provide signed consents/assents required to be videotaped. We encountered these constraints, among others, in our own data collection.

From a methodological perspective, analyzing classroom data collected under these circumstances requires taking alternative "routes." In our study, the teachers we videotaped at the different moments of the PD program were not always the same teachers, which limited our ability to make individual comparisons over time. The methodological alternative we took, as illustrated in this paper, was to consider the whole cohort of teachers as a single unit of analysis, thus focusing on general "tendencies" of change (Borko, 2004). In addition, given our interest in examining teachers' regular classroom practices, we videotaped lessons focused on a variety of topics (e.g., algebra, arithmetic, data analysis) and implemented using different formats (e.g., lectures, small group work, individual work). To address the broad range in teachers' lessons, we focused our analyses on aspects that could be potentially found in all lessons, regardless of content and format.

The design of the PD program featured in this study was guided by the features that researchers have identified as the common features of high-quality programs (e.g., Borko, 2004; Desimone, 2009; Higgins \& Parsons, 2009; Garet et al., 2001; Goldsmith et al., 2013). The program was composed of a series of three graduate level semester-long courses that required a great deal of work on the part of the teachers. The courses were highly interactive and inquiry-based, and intertwined mathematical content knowledge with mathematics education and pedagogy issues, with special emphasis on attending and responding to student mathematical thinking (Jacobs et al., 2010).

During our courses, teachers engaged in collaborative exploration and discussion on many topics related to mathematics and student mathematical thinking, and were required to complete a wide variety of assignments, both individually and collectively (e.g., challenge questions, student interviews, design of activity plans, implementation and analysis of 
learning activities). Our courses followed a non-prescriptive approach to PD. Course facilitators consistently provided teachers with constructive feedback, offering new hints and ideas for further reflection and discussion. And last but not least, we provided teachers with contexts for collegial sharing and collaboration, and offered them follow-up support beyond the duration of the courses.

In response to PD researchers' calls, this study provides evidence that the combination of these features seems to have affected positively a particular aspect of our participant teachers' classroom practice: their use of Cartesian graphs for the teaching of mathematics. Focusing on the data collected at the start and end of the PD program, we have presented a detailed analysis of the lessons where teachers chose to use graphs in class with no specific prompting, showing how the lessons videotaped at the end of the PD program presented uses of graphs that were qualitatively more sophisticated than the beginning lessons.

First, we identified a slight increase in the relative percentage of teachers using graphs in class, going from $20 \%$ at the start of the program to $33 \%$ at the end (13\% increment). We are aware that this result needs to be interpreted with caution. One reason is that the numbers of teachers videotaped at each time were uneven: 35 teachers at the start (seven of whom used graphs [20\%]) vs. 15 teachers at the end (five of whom used graphs [33\%]). The fact that participation was voluntary, added to the numerous practical constraints teachers face in their everyday work, did not allow us to gather datasets more similar in size.

Another reason why this $13 \%$ increase needs to be interpreted with caution is that we did not control for the content of the lessons videotaped, as justified above. For instance, one could argue that the increase might be due to the times of the school year when data were collected, and that mathematics topics taught in June (which coincides with the end of the school year and the end point of our data collection) might require more use of graphs than topics taught in January (which coincides with the mid-point of the school year and the beginning of our data collection). However, our evidence contradicts this interpretation. In fact, data collected at about the same time in the school year showed different relative frequencies of graph usage:

a) The data collected at the beginning of the PD program and end of Course 2 (see Table 1) were collected during similar times of the school year (January and December, respectively), but the use of graphs was $8 \%$ higher at the second data collection point.

b) Similarly, the data gathered at the end of Course 1 (see Table 1) and at the end of the PD program were collected around the end of the school year (May and June, respectively), but the use of graphs was $20 \%$ higher at the second data collection point, which in our view is a remarkable increase.

We therefore think the identified 13\% increment is important and speaks positively about the impact of the PD program featured in this study. Even more important is the fact that the ways in which they did so were more complex, as discussed below.

The results also suggest that participating in the PD program had an impact in promoting teachers' use of graphs at earlier grade levels, in particular in $6^{\text {th }}$ grade. As shown in Table 2, eight $6^{\text {th }}$ grade teachers were videotaped at the beginning of the program and none of them used graphs in class. In contrast, only four $6^{\text {th }}$ grade teachers were videotaped at the end, but two of them used graphs. In fact, these two teachers implemented activities specifically designed to introduce the Cartesian space to students. We consider this result to be evidence of the positive impact of teachers' participation in the PD program. The lack of evidence of graph use in $5^{\text {th }}$ grade, however, suggests that the impact was limited. Mathematics education researchers, curriculum designers, and teacher associations recommend teachers to introduce graphs early on in the curriculum (e.g., CCSSI, 2010; NCTM, 2000). For example, many textbooks and curriculum materials start to present graphs in $5^{\text {th }}$ grade. Further, some early algebra researchers have shown that students can meaningfully use graphs in $3^{\text {rd }}$ grade (Schliemann et al., 2007). Our program, therefore, should be further improved to better help $5^{\text {th }}$ grade teachers integrate graphs in their teaching.

We have also identified differences in two areas that directly connect with the "core" ideas of the PD program. One is the use of graphs in modeling and application activities (Blum, 2002), and the other is the use of graphs in connection with multiple representations (Ryken, 2009; Teixidor-i-Bigas et al., 2013).

Regarding the first area, participating in PD seems to have helped teachers move from activities where graphs are merely used to represent or translate given mathematical information (as illustrated by Mary's activity on graphing equations; Figure 4) to activities where graphs play a crucial role in exploring, analyzing, or modeling real life situations (as illustrated by Pearl's modeling activity with pennies and spaghetti; Figure 5). In the Results section, we described these activities as "closed" and "open-ended," depending on the number of possible solutions (one vs. multiple). We could argue that graphs at the start of the program were used in the context of rote exercises, where the main goal was to foster students' mastery of procedural skills (e.g., plotting points, drawing function lines), whereas at 
the end, graphs were used as tools to tackle actual problems, where complex mathematical processes were involved (e.g., predicting, finding patterns, generalizing).

Regarding the use of multiple representations, the results suggest that the PD program fostered teachers' ability to establish links between graphs and other representations. As illustrated by Karen and Carol's lessons (Figure 6), graphs played a peripheral role at the beginning of the program, being used only once during the lessons, generally briefly, and with the goal of illustrating ideas previously explained algebraically. In contrast, teachers displayed a much more interactive use of graphs by end of the program, establishing a continuous back-and-forth between graphs and other representations. Brigitte's lesson was presented as an exemplary case (Figure 7). The way she orchestrated the "Algebra Walk Activity," which was designed to help students establish connections between graphs and other representations, seems perfectly consistent with proposals by researchers who describe the power of multiple representations (Ryken, 2009; Teixidor-i-Bigas et al., 2013).

Finally, as shown in the analysis of teachers' lesson plans and their classroom talk, participating in the PD program seems to have helped teachers increase their awareness of the importance of graphs and functions for the teaching and learning of mathematics. At the start of the program, there were some teachers who implemented activities involving graphs. Most of them were taken from textbooks, which might indicate that the teachers had not explicitly considered the goal/s of including graphs in the lesson. None of these teachers provided explanations (neither written nor verbal) as to why and how graphs would be relevant to tackle the mathematical content at hand. In contrast, most teachers who used graphs by the end of the program provided explanations along these lines, as illustrated in Annette and Gabriella's lesson plans (Figures 2 and 3), as well as Zeus and Gabriella's classroom talk.

In connection with the literature on students' difficulties with graphs (e.g., Bell \& Janvier, 1981; Leinhardt et al., 1990) and proposals towards the integration of symbolic-algebraic notation and graphs (Schwartz \& Yerushalmy, 1992; Yerushalmy \& Schwartz, 1993), we speculate that ways of teaching graphs as the ones identified in teachers' lessons at the start of the PD program might be, at least to a certain extent, responsible for the challenges students commonly encounter. These ways of teaching might wrongly convey to students the view that graphs are representations of isolated data points. On the other hand, teaching approaches as the ones identified by the end of the PD courses, where graphs are used within modeling and application problems and in connection to other representations, would be more likely to convey the idea that graphs depict functional relationships between two variables and will promote a deeper understanding of algebra and functions among students. Future studies should examine whether or not this is the case.

With all the caveats that this research requires, we argue that the shifts in teachers' use of graphs might be due, at least in part, to their participation in the PD courses. Even though during the program we never explicitly recommended teachers to use more graphs in class, or to use graphs in a particular way, participating in PD seems to have fostered moves in the direction intended. We conclude that participating in PD that included the general features described in the Introduction section might have had a positive impact on teachers' instructional practice. Thus, the present study might inform the design and implementation of other PD programs, not only in mathematics but in other content areas as well.

\section{Limitations and Future Research}

There are obviously important questions that cannot be answered with the data available. To what extent is the impact of the PD program on teachers' use of graphs significant? Could the impact have been greater if the program had been different (for example, if we had focused on different mathematical topics, or implemented different assignments, or interacted in person with the teachers more/less often)? Given the resources available, it was not possible for us to observe the teaching of a comparable control group, or to have different cohorts of teachers following different versions of our program. It is therefore necessary to develop meta-analysis as the ones conducted by Borko (2004) or Goldsmith et al. (2013), in which the results presented in this paper are compared with results from other PD initiatives.

Another important question has to do with the durability of the effects of participating in PD. Will teachers continue to make a sophisticated use of graphs in the future, as described in this paper? It is obviously impossible to answer this question with the evidence available. However, we have some compelling evidence from an external evaluation of our program (Zuman \& Schliemann, 2013) showing not only durability beyond program completion, but also further improvement in instructional practices. A subset of 28 teachers who participated in the program was observed six months after program completion. The results showed a significant improvement in teachers' use of multiple representations (including graphs) with respect to data collected at the start of the PD program (January 2011) and also at the end (June 2012). These findings suggest that it might take teachers some time to fully apply the ideas learned from PD programs to their own teaching.

Future research should replicate the present study with teachers enrolled in PD programs with similar and different characteristics. Analyses of this nature will contribute to a better understanding of the mechanisms by which teachers' work in PD informs and improves their instructional practice (Darling-Hammond, 2010; Kazemi \& Hubbard, 2008). 


\section{Acknowledgements}

This study was conducted while the first author was a Postdoctoral Associate at Tufts University. The research was founded by the National Science Foundation (NSF), Grant \# DUE-0962863, "The Poincaré Institute: A Partnership for Mathematics Education." The ideas expressed herein are those of the authors and do not necessarily reflect the ideas of the funding agency.

\section{References}

Battista, M. T., \& Clements, D. H. (1991). Using spatial imagery in geometric reasoning. The Arithmetic Teacher, 39(3), $18-21$.

Bell, A., \& Janvier, C. (1981). The interpretation of graphs representing situations. For the Learning of Mathematics, 2, 34-42.

Bell, C. A., Wilson, S., Higgins, T., \& McCoach, B. (2010). Measuring the effects of professional development on teacher knowledge: The case of Developing Mathematical Ideas. Journal for Research in Mathematics Education, 41(5), 479-498.

Blum, W. (2002). ICMI Study 14: Applications and modelling in mathematics education-Discussion document. Educational Studies in Mathematics, 51, 149-171. http://dx.doi.org/10.1023/A:1022435827400

Borko, H. (2004). Professional development and teacher learning: Mapping the terrain. Educational Researcher, 33(8), $3-15$.

Brizuela, B. M., \& Gravel, B. (2013). "Show Me What You Know": Exploring Representations across STEM Disciplines. New York: Teachers College Press.

Carpenter, T. P., Fennema, E., Peterson, P. L., Chiang, C., \& Loef, M. (1989). Using knowledge of children's mathematical thinking in classroom teaching: An experimental study. American Educational Research Journal, 26, 499-532. http://dx.doi.org/10.3102/00028312026004499

Chapman, O. (2010). Teachers' self-representations in teaching mathematics. Journal of Mathematics Teacher Education, 13(4), 289-294.

Common Core State Standards Initiative [CCSSI] (2010). Common Core State Standards for Mathematics. Washington, DC: National Governors Association Center for Best Practices and the Council of Chief State School Officers.

Darling, H. L. (2010). Teacher Education and the American Future. Journal of Teacher Education, 61(1-2), 35-47. http://dx.doi.org/10.1177/0022487109348024

Dede, C., Ketelhut, D. J., Whitehouse, P., Breit, L., \& McCloskey, E. M. (2009). A Research Agenda for Online Teacher Professional Development. Journal of Teacher Education, 60(1), 8-19. http://dx.doi.org/10.1177/0022487108327554

Desimone, L. M. (2009). Improving impact studies of teachers' professional development: Toward better conceptualisations and measures. Educational Researcher, 38(3), 181-199. http://dx.doi.org/10.3102/0013189X08331140

Duncan, O. G. (2010). Teachers' views on dynamically linked multiple representations, pedagogical practices and students' understanding of mathematics using TI-Nspire in Scottish secondary schools. The International Journal on Mathematics Education, 42, 763-774.

Garet, M. S., Porter, A. C., Desimone, L., Birman, B. F., \& Yoon, K. S. (2001). What Makes Professional Development Effective? Results From a National Sample of Teachers. American Educational Research Journal, 38, 915 -945. http://dx.doi.org/10.3102/00028312038004915

Goldsmith, L. T., Doerr, H. M., \& Lewis, C. C. (2014). Mathematics teachers' learning: A conceptual framework and synthesis of research. Journal of Mathematics Teacher Education, 17(1), 5-36. http://dx.doi.org/10.1007/s10857-013-9245-4

Higgins, J., \& Parsons, R. (2009). A successful professional development model in mathematics. A system-wide New Zealand case. Journal of Teacher Education, 60(3), 231-242. http://dx.doi.org/10.1177/0022487109336894

Hoekstra, A., \& Korthagen, F. (2011). Teacher Learning in a Context of Educational Change: Informal Learning Versus Systematically Supported Learning. Journal of Teacher Education, 62(1), 76-92. http://dx.doi.org/10.1177/0022487110382917

Jacobs, V. R., Lamb, L. C., \& Phillipp, R. A. (2010). Professional noticing of children's mathematical thinking. Journal for Research in Mathematics Education, 41, 169-202. 
Kaput, J. (1987). Representation systems and mathematics. In C. Janvier (Ed.), Problems of representation in the teaching and learning of mathematics (pp. 19-26). Hillsdale, NJ: Lawrence Erlbaum Associates

Kaput, J. (1998). Representations, inscriptions, descriptions and learning: A kaleidoscope of windows. Journal of Mathematical Behavior, 17(2), 265- 281. http://dx.doi.org/10.1016/S0364-0213(99)80062-7

Kazemi, E., \& Hubbard, A. (2008). New directions for the design and study of Professional Development. Attending to the coevolution of teachers' participation across contexts. Journal of Teacher Education, 59(5), 428-441. http://dx.doi.org/10.1177/0022487108324330

Kerslake, D. (1981). Graphs. In K. M. Hart (Ed.), Children's understanding of mathematics concepts (pp. 120-136). London: John Murray.

Leinhardt, G., Zaslavsky, O., \& Stein, M. K. (1990). Functions, graphs, and graphing: Tasks, learning, and teaching. Review of Educational Research, 60(1), 1-64. http://dx.doi.org/10.3102/00346543060001001

Lewis, C., Perry, R., \& Murata, A. (2006). How should research contribute to instructional improvement? The case of lesson study. Educational Researcher, 35, 3-14. http://dx.doi.org/10.3102/0013189X035002023

National Council of Teachers of Mathematics [NCTM] (2000). Principles and Standards for School Mathematics. Reston, VA: NCTM Publication.

Organization for Economic Co-Operation and Development [OECD] (2006). Assessing scientific, reading and mathematical literacy: A framework for PISA 2006. Paris: OECD Publishing.

Rico, L. (2009). Sobre las nociones de representación y comprensión en la investigación en educación matemática [On the notions of representation and understanding in mathematics education research]. PNA, 4(1), 1-14.

Ryken, A. (2009). Multiple representations as sites for teacher reflection about mathematics learning. Journal of Mathematics Teacher Education, 12(5), 347-364. http://dx.doi.org/10.1007/s10857-009-9107-2

Saxe, G. B., Gearhart, M., \& Nasir, N. (2001). Enhancing students' understanding of mathematics: A study of three contrasting approaches to professional support. Journal of Mathematics Teacher Education, 4, 55-79. http://dx.doi.org/10.1023/A:1011493204582

Schliemann A. D., Carraher D. W., \& Brizuela B. M. (2007). Bringing out the algebraic character of arithmetic: From children's ideas to classroom practice. Hillsdale, NJ: Erlbaum.

Schliemann, A. D., \& Carraher, D. W. (2002). The evolution of mathematical understanding: Everyday versus idealized reasoning. Developmental Review, 22(2), 242-266. http://dx.doi.org/10.1006/drev.2002.0547

Schwartz, J., \& Yerushalmy, M. (1992). Getting students to function in and with algebra. In G. Harel \& E. Dubinsky (Eds.), The concept of function: Aspects of epistemology and pedagogy (MAA Notes, 25, pp. 261-289). Washington, DC: Mathematical Association of America.

Stylianou, D. A. (2010). Teachers' conceptions of representation in middle school mathematics. Journal of Mathematics Teacher Education, 13, 325-343. http://dx.doi.org/10.1007/s10857-010-9143-y

Teixidor-i-Bigas, M., Schliemann, A. D., \& Carraher, D. (2013). Integrating disciplinary perspectives: The Poincaré Institute for Mathematics Education. The Mathematics Enthusiast, 10(3), 519-561.

U. S. Congress. (2001). No Child Left Behind Act of 2001. Public Law 107-110. 107th Congress. Washington, DC: Government Printing Office.

Wise, V. L., Spiegel, A. N., \& Bruning, R. H. (1999). Using Teacher Reflective Practice to Evaluate Professional Development in Mathematics and Science. Journal of Teacher Education, 50, 42-49. http://dx.doi.org/10.1177/002248719905000105

Yerushalmy, M., \& Schwartz, J. (1993). Seizing the opportunity to make algebra mathematically and pedagogically interesting. In T. Romberg, E. Fennema, \& T. Carpenter (Eds.) Integrating Research on the Graphical Representation of Functions (pp. 67-97). Hillsdale, NJ, Erlbaum.

Zuman, J., \& Schliemann, A. D. (2013). Impact of the Poincare Institute for Mathematics Education on Teacher Instruction. Presentation at the 2013 MSP Learning Network Conference. National Science Foundation, Washington, DC (February 11-12).

\section{(cc) BY}

This work is licensed under a Creative Commons Attribution 3.0 License. 